Original Research

\title{
The association between social support and medication adherence in patients with hypertension:
}

\author{
A systematic review \\ Wejdan SHAHIN (iD), Gerard A. KENNEDY (D), leva STUPANS (D) \\ Received (first version): 21-Jan-2021_ Accepted: 6-Jun-2021_ Published online: 22-Jun-2021
}

\begin{abstract}
Background: Medication adherence is a primary determinant of treatment success in hypertensive patients. One of the challenges for healthcare providers that has received little attention is the impact of patients' social supports on medication adherence.

Objective: This review evaluates the impact of patients' social supports on medication adherence in hypertensive patients.

Methods: A systematic review methodology was used. Pubmed, CINAHL, Embase, and PsycINFO databases were searched systematically for relevant articles. The outcome measure in the studies was medication adherence in hypertension.

Results: From 1155 articles, 238 were retained for further assessment, and finally, 14 met the inclusion criteria. Statistically significant positive associations between medication adherence and social support were found in nine studies $(p<0.05)$.

Conclusions: This review evaluated the impact of social support on medication adherence and highlighted gaps in the literature regarding the impact of social support on adherence. Family members or peer support may promote better adherence in some patient groups. This review suggests that healthcare providers may need to consider whether patients have appropriate social supports in place which will assist them adhering to and benefiting from treatment recommendations.
\end{abstract}

Keywords

Social Support; Medication Adherence; Health Personnel; Hypertension; Outcome Assessment, Health Care; Systematic Reviews as Topic; Australia

\section{INTRODUCTION}

Chronic illnesses are one of the major health challenges worldwide, with numbers of people affected steadily increasing. Many of the most prevalent chronic illnesses, such as hypertension, diabetes, arthritis, and asthma involve a significant management component, that includes medication adherence, physical activity, and specific disease-related behaviours. ${ }^{1}$

Hypertension is a worldwide public-health challenge and is a major modifiable risk factor in cardiovascular related disease and death. ${ }^{2}$ Uncontrolled hypertension is believed to be the cause of $13.5 \%$ of premature deaths and $6 \%$ of lost years of life due to death or disability. ${ }^{3}$

Non-adherence to medications is well established as an important contributor to poorly controlled hypertension. ${ }^{4}$ Multiple factors contribute to medication non-adherence including poverty, low level of education, unemployment, and lack of social support. ${ }^{5}$ Patients from minority groups may find that adherence to medications is particularly challenging particularly if coupled with poor living conditions. ${ }^{6}$ These patients report lower involvement in medical decision making, poorer communication with physicians, lower levels of trust in physicians, and lower levels of satisfaction with care, and lower levels of adherence to medication regimen.

Wejdan SHAHIN School of Health \& Biomedical Sciences, RMIT University. Bundoora, VIC (Australia). wejdan.shahin@rmit.edu.au Gerard A. KENNEDY. School of Health \& Biomedical Sciences,

RMIT University. Bundoora, VIC (Australia).

g.kennedy@federation.edu.au

leva STUPANS. School of Health \& Biomedical Sciences, RMIT

University. Bundoora, VIC (Australia). ieva.stupans@rmit.edu.au
Although effective communication between healthcare providers and patients makes a major contribution to medication adherence, adequate social support and interaction between patients and their families has been shown to support the uptake of positive health initiatives, and improve the quality of patients' lives. ${ }^{8}$ In addition to family support, social support can also be provided by friends and peers, as well as healthcare professionals and organisations. ${ }^{9}$ Thus, social support is multifaceted and may help patients remain active in their care when faced with physical, social and economic vulnerabilities. ${ }^{10}$

Family members can support hypertensive patients in several ways including, encouraging them positively, monitoring health, sharing information, helping in moments of crisis and health care generally, including care with diet, physical exercise, and adherence to a medication regimen. In addition, family can transmit strength and courage to patients, which make them feel safe and supported in the illness experience. ${ }^{11}$ Patients receiving support from family members may feel a greater sense of self-worth, and this can encourage optimism about treatment. $^{12}$ Family members regulate each other's behaviours and provide information and encouragement to behave in healthier ways and to more effectively utilize health care services. ${ }^{13}$

A previous systematic review evaluated the impact of social support on various health outcomes in patients with diabetes mellitus type 2 , and found that increasing social support yielded favourable results including, increased selfmanagement, medication adherence, and adoption of nutritional advice and active lifestyles. ${ }^{14}$ Another systematic review that examined observational studies also 
found social support has a positive impact on the management of diabetes mellitus type 2 and patients' adherence to the healthcare advice. ${ }^{15}$

There is some evidence to suggest that healthcare systems, educational programs and participating in various groups are effective in improving hypertension control and treatment adherence. ${ }^{16}$ However, with increasing pressure on healthcare systems, interventions become expensive to provide, may be too rigid and risk not engaging some patients from diverse backgrounds. In contrast, friends or family support is 'free', readily available and specific to the individual. ${ }^{15}$ Evaluating the effect of social support on hypertensive patients may be useful in enhancing medication adherence.

An earlier review has evaluated the impact of social support on medication adherence, however it included only articles published before 2010. ${ }^{17}$ Since 2010, several studies have been published that have also examined the impact of social support on medication adherence. Therefore, in this review, we updated the earlier review to consider findings from more recent literature about social support and medication adherence.

A meta-analysis examined the impact of social support via marital status on medication adherence in patients with hypertension. ${ }^{18}$ Therefore, this review aimed to evaluate the impact of a broad range of social support provided by family, friends and the healthcare system on medication adherence in patients with hypertension.

\section{METHODS}

\section{Search protocol and design}

This review follows The Preferred Reporting Items for Systematic Reviews and Meta- Analyses (PRISMA) guidelines. ${ }^{19}$ To identify the impact of social support on medication adherence in patients with hypertension, we searched the electronic databases (CINHAL, PubMed, Embase, and PsycINFO) extensively and systematically. Table 1 shows the combination of search terms that were used to source the relevant literature. The search was carried out in December 2020, updated in May 2021, and included papers reported in the data bases to the first of May 2021. The search was limited to include articles published from January 2010 to the first of May 2021; a previous systematic review that evaluated the impact of social support on medication adherence included articles published before $2010 .^{17}$

\section{Study selection}

Titles and abstracts were screened initially to select the studies that met the inclusion criteria. Subsequently, copies of the full text papers deemed to be potentially relevant, were independently fully analyzed. Two authors assessed the eligibility of the final articles. Any disagreements were resolved by reaching consensus with the assistance of a third author. Reference lists of articles included were searched manually and one further reference was retrieved.

\section{Inclusion criteria}

Articles were included if: (1) they focused on social support; (2) included a clear method of how medication adherence was measured; (3) addressed the association of social support and medication adherence; and (4) included hypertension.

\section{Exclusion criteria}

Articles were excluded if: (1) they were not peer-reviewed articles; (2) published before 2010; (3) written in a language other than English; (4) focused on illnesses other than hypertension; (5) participants were not adults; and (6) measured factors other than social support.

\section{Data extraction process}

Data were extracted from each eligible paper. Demographics, design of the study and the tools used to measure medication adherence are shown in Table 2 . The social support interventions and tools which evaluate social support are presented in Table 3. A summary of the major findings and the direction of associations of medication adherence with social support for the included studies are shown in Table 4.

\section{Risk of bias in individual studies}

Mixed Methods Appraisal Tool (MMAT) version 2018 was used to assess each of the eligible studies included in this review. $^{20}$ For randomized controlled trials, the following five components were assessed: (1) if the randomization was appropriately performed (2) if the groups were comparable at baseline (3) if there were complete outcome data (4) if the outcome assessors were blinded to the intervention provided; (5) if the participants adhered to the assigned intervention. For quantitative descriptive studies, the following five criteria were assessed: (1) if the strategy of selecting sample was relevant to address the research question; (2) if the sample was representative of the target population; (3) if the measurements were appropriate; (4) if the risk on non-response bias was low; and (5) if the

\begin{tabular}{|l|l|}
\hline \multicolumn{1}{|c|}{ Table 1. Review search terms and databases reviewed } \\
\hline \multicolumn{1}{|c|}{ Database } & \multicolumn{1}{|c|}{ Search terms } \\
\hline PubMed & $\begin{array}{l}((((((\text { therapeutic adherence) OR (medication compliance)) OR (medication adherence)) OR (treatment } \\
\text { adherence))) AND (((((friend support) OR (peer support)) OR (family involvement)) OR (family } \\
\text { engagement)) OR (family support)) OR (social support))) AND (hypertension) }\end{array}$ \\
\hline CINAHL with full text & $\begin{array}{l}\text { ((social support OR (family support or family involvement or family engagement) OR peer support) AND } \\
\text { (medication adherence OR medication compliance OR therapeutic adherence OR treatment adherence) } \\
\text { AND hypertension }\end{array}$ \\
\hline Embase & $\begin{array}{l}\text { (therapeutic AND adherence OR (medication AND adherence) OR 'medication compliance' OR } \\
\text { (treatment AND adherence) AND (peer AND support OR (social AND support) OR 'family support' OR } \\
\text { (friend AND support) AND hypertension }\end{array}$ \\
\hline PsycINFO & $\begin{array}{l}\text { (((social support) OR (family social support) OR (friend support) OR (peer support)) AND (hypertension) } \\
\text { AND (((medication AND adherence) OR (therapeutic adherence AND compliance)) }\end{array}$ \\
\hline
\end{tabular}




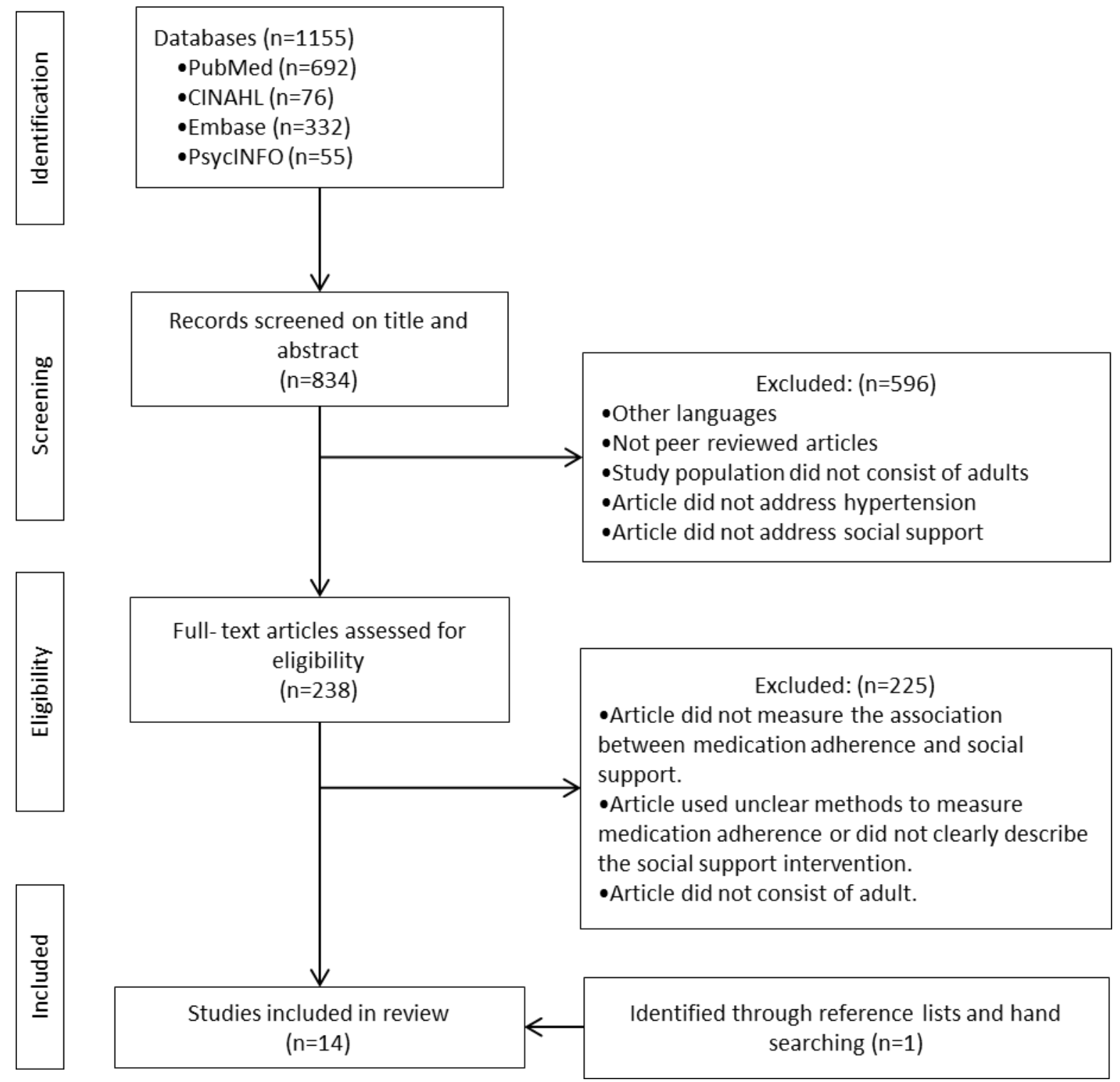

Figure 1. PRISMA flow chart of the literature search and study selection

statistical analyses appropriately answered the research question. Two researchers independently scored articles, and scores were compared to identify differences, which were resolved through discussion. The score was assigned for each paper in this review based on the percentage of criteria that were met for the relevant study design. Then, papers were categorized into one of three categories, where low quality was considered to be a score between $0 \%$ and $40 \%$, medium quality between $41 \%$ and $70 \%$, and high quality between $71 \%$ and $100 \%$.

\section{RESULTS}

A total of 1,155 articles were located via the literature search and the titles and abstracts of the 834 articles were reviewed after removing 321 duplicates. A detailed assessment of 238 full-text articles resulted in the elimination of additional 225 articles. A final set of 14 articles that met the inclusion criteria were selected. Figure 1 shows PRISMA Flow Chart that describes article screening and exclusion process in detail.
Ten out of fourteen studies selected were cross-sectional, including surveys, another four studies were interventional randomized controlled trials. Family was the most frequently investigated provider of support reported in 10 of the studies (Table 2).

Two studies were conducted in Nigeria, two in MiddleEastern countries, one in China, two in Turkey, one in Spain, one in Poland, two in the United States, one in Ethiopia, one in Malaysia, and one in Indonesia (Table 2). $8,10,21-32$

Fourteen studies evaluated the impact of social support on medication adherence; ten cross-sectional studies and four interventional studies. ${ }^{8,10,22-32}$ The cross-sectional studies included in this study used different scales and questionnaires to measure social support as shown in Table 3 , while in the interventional studies, family members, friends or pharmacists were designated as supervisors of hypertensive patients. Family members or friends educated patients about the illness and medications, reminded them 


\begin{tabular}{|c|c|c|c|c|c|c|c|}
\hline \multirow[b]{2}{*}{ Ref } & \multirow[b]{2}{*}{ Design of study } & \multicolumn{5}{|c|}{ Sociodemographic characteristics } & \multirow[b]{2}{*}{ Measurement of medication adherence } \\
\hline & & Age (M) & $\begin{array}{l}\text { Sample } \\
\text { size }\end{array}$ & $\%$ Male & $\begin{array}{l}\text { Participants } \\
\text { origin/cultural } \\
\text { groups }\end{array}$ & $\begin{array}{l}\text { Duration of } \\
\text { hypertension }\end{array}$ & \\
\hline 22 & $\begin{array}{l}\text { Cross-sectional } \\
\text { study }\end{array}$ & $>28 y$ & 538 & $39.1 \%$ & $\begin{array}{l}\text { Palestinian citizens- } \\
\text { Gaza }\end{array}$ & $>1$ year & $\begin{array}{l}\text { Morisky Medication Adherence Scale } \\
\text { (MMAS-8) }\end{array}$ \\
\hline 30 & $\begin{array}{l}\text { Cross-sectional } \\
\text { study }\end{array}$ & 57.6 & 989 & $47.3 \%$ & Ethiopian- Ethiopia & - & $\begin{array}{l}\text { Morisky Medication Adherence Scale } \\
\text { (MMAS-8) }\end{array}$ \\
\hline 8 & Descriptive study & 64.9 & 259 & $41.3 \%$ & $\begin{array}{l}\text { Turkish patients- } \\
\text { Turkey }\end{array}$ & $>1$ year & Medication Adherence Self-Efficacy Scale \\
\hline 27 & $\begin{array}{l}\text { Cross-sectional } \\
\text { study }\end{array}$ & 72.1 & 150 & $44 \%$ & $\begin{array}{l}\text { Older patients } \\
\text { hospitalized in Poland }\end{array}$ & $>6$ years & $\begin{array}{l}\text { Hill-Bone Compliance to High Blood } \\
\text { Pressure Therapy Scale (Hill-Bone CHBPTS) }\end{array}$ \\
\hline 24 & $\begin{array}{l}\text { Cluster } \\
\text { Randomized trial }\end{array}$ & 67.3 & 455 & $47.6 \%$ & $\begin{array}{l}\text { Rural Chinese } \\
\text { patients-China }\end{array}$ & - & $\begin{array}{l}\text { Face to face interview questions after 6-12 } \\
\text { months about missing pills or not taking } \\
\text { prescribed medications }\end{array}$ \\
\hline 10 & $\begin{array}{l}\text { Cross-sectional } \\
\text { questionnaire- } \\
\text { guided interview }\end{array}$ & 62.8 & 250 & $43.2 \%$ & $\begin{array}{l}\text { Nigerian patients in } \\
\text { Nigeria }\end{array}$ & - & $\begin{array}{l}\text { Morisky Modified Adherence Scale (MMAS- } \\
\text { 4) }\end{array}$ \\
\hline 21 & $\begin{array}{l}\text { Descriptive cross- } \\
\text { sectional study }\end{array}$ & 60.6 & 420 & $49 \%$ & $\begin{array}{l}\text { Nigerian patients in } \\
\text { Nigeria }\end{array}$ & $\begin{array}{l}<1 \mathrm{y} ; 10.2 \% \\
1-5 y ; 55.1 \% \\
6-10 y ; 22.1 \% \\
>10 y ; 12.5 \%\end{array}$ & $\begin{array}{l}\text { Estimated manually by means of patient } \\
\text { self-report }\end{array}$ \\
\hline 26 & \begin{tabular}{|l} 
Cluster \\
Randomized trial
\end{tabular} & $>50 y$ & 264 & $52 \%$ & $\begin{array}{l}\text { Patients from multi- } \\
\text { center in Spain }\end{array}$ & $11 \mathrm{y}$ & Haynes-Sackett test \\
\hline 23 & $\begin{array}{l}\text { Randomized } \\
\text { clinical trial study }\end{array}$ & $>18 y$ & 64 & - & $\begin{array}{l}\text { Iranian patients in } \\
\text { Iran }\end{array}$ & - & $\begin{array}{l}\text { Ten questions within a questionnaire about } \\
\text { medication adherence }\end{array}$ \\
\hline 25 & $\begin{array}{l}\text { Cross-sectional } \\
\text { study }\end{array}$ & $62.64 \pm 10.66$ & 397 & $33.5 \%$ & $\begin{array}{l}\text { Turkish patients in } \\
\text { Turkey }\end{array}$ & Average of 9.6 y & Medication Adherence Self-Efficacy Scale \\
\hline 28 & $\begin{array}{l}\text { Cross-sectional } \\
\text { study }\end{array}$ & $49 y$ & 120 & $22.5 \%$ & $\begin{array}{l}\text { African American- } \\
\text { USA }\end{array}$ & Average of $8.4 \mathrm{y}$ & $\begin{array}{l}\text { Hill-Bone Compliance to High Blood } \\
\text { Pressure Therapy Scale }\end{array}$ \\
\hline 29 & $\begin{array}{l}\text { Randomized } \\
\text { controlled trial }\end{array}$ & $21-85 y$ & 584 & $45.7 \%$ & $\begin{array}{l}\text { American patients in } \\
\text { USA }\end{array}$ & - & $\begin{array}{l}\text { Morisky self-reported adherence } \\
\text { questionnaire }\end{array}$ \\
\hline 31 & $\begin{array}{l}\text { Cross-sectional } \\
\text { study }\end{array}$ & $57.6 \pm 13.5$ & 300 & $59 \%$ & $\begin{array}{l}\text { Malaysian patients in } \\
\text { Malysia }\end{array}$ & $>12$ months & $\begin{array}{l}\text { 8-item Morisky Medication Adherence } \\
\text { Scale }\end{array}$ \\
\hline 32 & $\begin{array}{l}\text { Cross- sectional } \\
\text { study }\end{array}$ & $>35 y$ & 200 & $39.5 \%$ & $\begin{array}{l}\text { Indonesian patients } \\
\text { in Indonesia }\end{array}$ & - & $\begin{array}{l}\text { Medication adherence questionnaire } \\
\text { addressing the reasons for non-adherence }\end{array}$ \\
\hline
\end{tabular}

to take medications, provided additional health information, and supported patient behaviour (Table 3).

Different tools were used to measure social support including, Health beliefs Model Construct, Multidimensional Perceived Social Support Scale, Perceived Social Support Family Scale, and Enhancing Recovery in Coronary Heart Disease Social Support Inventory. In two studies, questionnaires were used to ask the participants about living with one or more of family members, or about the most available source of social support (Table 3). In addition, medication adherence was measured using various self-report measures (Table 2).

The most frequently examined support was family support. Nine studies found positive association between family support and medication adherence. However, two cross sectional studies found no significant associations between family support and medication adherence. ${ }^{10,28}$ In one study (Adisa et al., 2017) family support was mentioned as the most accessible support, while the financial support was the most desired even though no significant association with medication adherence was reported.

Healthcare support was mentioned in two studies, one conducted in Ghaza and the second carried out in USA. ${ }^{22,29}$ There was no significant association between this source of support and adherence to medication in the first study, while positive but weak association was reported between social support provided by the pharmacists and medication adherence in the second study. ${ }^{22,29}$

The impact of peer support groups on medication adherence was reported in three studies; two cross sectional studies carried out in Turkey and one interventional study conducted in Iran. ${ }^{8,23,25}$ The findings of three studies consistently showed that peer support positively influenced medication adherence (Table 4).

Findings for a risk of bias across the quantitative descriptive and randomized controlled studies are presented in Table 5 and Table 6. All papers were of high quality. All descriptive studies included in this review provided a clear inclusion criterion and described the settings clearly. Moreover, all the included studies used appropriate statistical analyses. Reliable and valid questionnaires were used to measure the outcome variables. A representative sample was used in five of eight studies which reported the possibility of generalizing the findings (Table 5). In all the included randomized controlled studies, randomization was performed, the groups were compared at the baseline, and participants were described as adherent to the assigned interventions. However, in only one of four randomized studies were the assessors blinded to the interventions (Table 6). 


\begin{tabular}{|c|c|c|}
\hline Ref & Social support evaluation tools & Social support interventions \\
\hline 22 & $\begin{array}{l}\text { A questionnaire- Health Beliefs Model (HBM) constructs: } \\
\text { perceived barriers and benefits }\end{array}$ & Not applicable \\
\hline 30 & Not applicable & Engaging family members in the treatment plan \\
\hline 8 & $\begin{array}{l}\text { A questionnaire- Multidimensional Perceived } \\
\text { Social Support Scale (MSPSS) }\end{array}$ & Not applicable \\
\hline 27 & A questionnaire- Living with a family member or not & Not applicable \\
\hline 24 & Not applicable & $\begin{array}{l}\text { (1) A family member was designated as a supervisor; (2) trained the } \\
\text { supervisor and educated them about hypertension, treatment, and } \\
\text { side effects; (3) designated the supervisor as a reminder for the } \\
\text { patient to take the medications and measure blood pressure }\end{array}$ \\
\hline 10 & A questionnaire - Most available source of social support & Not applicable \\
\hline 21 & A questionnaire - Perceived Social Support Family Scale (PSS-FS) & Not applicable \\
\hline 26 & Not applicable & $\begin{array}{l}\text { A family member was designated to support adherence behavior, and } \\
\text { provided educational information to patients }\end{array}$ \\
\hline 23 & Not applicable & $\begin{array}{l}\text { (1) Educated peers about hypertension, health in general , } \\
\text { medications, diet and excercises; (2) Designated them as leaders for } \\
\text { patients }\end{array}$ \\
\hline 25 & $\begin{array}{l}\text { A questionnaire- Multidimensional Perceived } \\
\text { Social Support Scale (MSPSS) }\end{array}$ & Not applicable \\
\hline 28 & $\begin{array}{l}\text { A questionnaire- Enhancing Recovery in Coronary Heart Disease } \\
\text { Social Support Inventory }\end{array}$ & Not applicable \\
\hline 29 & Not applicable & $\begin{array}{l}\text { Pharmacists support by providing intensified hypertension } \\
\text { management and drug adherence counseling to patients in the } \\
\text { intervention group }\end{array}$ \\
\hline 31 & Multidimensional Scale of Perceived Social Support & Not applicable \\
\hline 32 & A questionnaire to report receiving family supoport & Not applicable \\
\hline
\end{tabular}

\section{DISCUSSION}

The included papers in this review reported significant positive associations between social support and medication adherence in patients with hypertension. Managing and using social support is important for improving medication adherence and the successful longer- term management of hypertension.

In the fourteen papers reviewed, family support was the most predictable and favourable factor positively influencing medication adherence. Eleven studies found a positive impact of family support on medication adherence. The results of four interventional studies in this review demonstrated that emotional social support from family

\begin{tabular}{|c|c|c|}
\hline Ref & Included factor & Association between factors and medication adherence \\
\hline \multirow[t]{2}{*}{22} & Social support-Family & $\begin{array}{l}\text { Significant positive association between social support and medication adherence }(\mathrm{OR}, 2.87 ; 95 \% \mathrm{Cl} \text {, } \\
2.66-3.09)\end{array}$ \\
\hline & $\begin{array}{l}\text { Social support- Healthcare } \\
\text { support }\end{array}$ & $\begin{array}{l}\text { No significant association between healthcare support and medication adherence }(\mathrm{OR}, 1.18 ; 95 \% \mathrm{Cl} \text {, } \\
0.75-1.86)\end{array}$ \\
\hline 30 & Social support-Family & $\begin{array}{l}\text { Significant positive association between social support and medication adherence }(\mathrm{OR}, 1.65 ; 95 \% \mathrm{Cl} \text {, } \\
1.23-2.22)\end{array}$ \\
\hline \multirow[t]{2}{*}{8} & Social support- Family & Significant positive associations between family support and medication adherence $(r=0.34, p=0.0001)$ \\
\hline & Social support- Friends & Significant positive association between friends support and medication adherence $(r=0.30, p=0.0001)$ \\
\hline 27 & Social support-Family & Significant positive association between social support and medication adherence $(p<0.05)$ \\
\hline 24 & Social support-Family & $\begin{array}{l}\text { Significant positive association between social support and medication adherence (OR: } 1.74,95 \% \mathrm{Cl} \text { : } \\
0.91-3.32 \text { ) }\end{array}$ \\
\hline \multirow[t]{2}{*}{10} & $\begin{array}{l}\text { Social support-Family } \\
\text { support }\end{array}$ & No significant association between family support and medication adherence $(p=0.135)$ \\
\hline & Social support- Financial & No significant association between financial support and medication adherence $(p=0.44)$ \\
\hline 21 & Social support-Family & Significant positive association between social support and medication adherence $(p<0.05)$ \\
\hline 26 & Social support-Family & $\begin{array}{l}\text { Significant positive association between social support and medication adherence (OR: } 1.91,95 \% \mathrm{Cl} \text { : } \\
1.19-3.05 \text { ) }\end{array}$ \\
\hline 23 & Social support- Peer & Significant positive association between peer support and medication adherence $(p<0.001)$ \\
\hline \multirow[t]{2}{*}{25} & Social support- Family & Significant positive association between family support and medication adherence $(p<0.05)$ \\
\hline & Social support- Friends & Significant positive association between friends support and medication adherence $(p<0.05)$ \\
\hline 28 & Social support & No significant association between social support and medication adherence $(p>0.05)$ \\
\hline 29 & Social support & Significant positive association between social support and medication adherence $(p<0.05)$ \\
\hline 31 & Social support & Significant positive association between social support and medication adherence $(r=0.181, p=0.003)$ \\
\hline 32 & Social support- Family & Significant positive association between family support and medication adherence $(p=0.000)$ \\
\hline
\end{tabular}




\begin{tabular}{|c|c|c|c|c|c|c|c|c|c|c|}
\hline Reference & 22 & 30 & 8 & 27 & 10 & 21 & 25 & 28 & 31 & 32 \\
\hline $\begin{array}{l}\text { Is the sampling strategy relevant to address the } \\
\text { research question? }\end{array}$ & Yes & Yes & Yes & Yes & Yes & Yes & Yes & Yes & Yes & Yes \\
\hline $\begin{array}{l}\text { Is the sample representative of the target } \\
\text { population? }\end{array}$ & Yes & Yes & No & No & Yes & Yes & Unk & Yes & No & Unk \\
\hline Are the measurements appropriate? & Yes & Yes & Yes & Yes & Yes & Yes & Yes & Yes & Yes & Yes \\
\hline Is the risk of non-response bias low? & Unk & Yes & Yes & Unk & No & Yes & Unk & Yes & Unk & Unk \\
\hline $\begin{array}{l}\text { Is the statistical analysis appropriate to answer } \\
\text { the research question? }\end{array}$ & Yes & Yes & Yes & Yes & Yes & Yes & Yes & Yes & Yes & Yes \\
\hline Score; \% high quality & 90 & 100 & 90 & 80 & 90 & 100 & 80 & 100 & 80 & 80 \\
\hline
\end{tabular}

members, friends, or healthcare providers improved medication adherence either by educating the patients, supporting their behaviour, or supervising and reminding them to take medications. This implies that the presence of family or friends may potentially be sufficient to change medication taking behaviour. This also suggests the importance of healthcare providers' support to ensure that patients are taking medications regularly.

Most of the reviewed studies focused on older adults. It should be considered that social support may be more important for older adults than for younger adults. Older adults are more likely to discuss health issues and symptoms with family members than with anyone else, family members often accompany older adults to medical appointments, and remind them to take their medications. ${ }^{1}$

In contrast with the previous findings, two cross-sectional studies in this review found no association of between family support and medication adherence. ${ }^{10,28}$ In addition, both financial and healthcare system support was not consistently associated with medication adherence. ${ }^{10,22}$

The reason for this discrepancy may due to the poor satisfaction of participants with the provided social support, or it may due to the relatively younger age of participants, in the other paper. ${ }^{10}$ These younger participants may have found social support less important than older participants. ${ }^{22}$

Different mechanisms have been reported in the literature to explain how social support influences adherence to medications including, buffering stress and allowing an individual to engage in more adaptive sick-role behaviours and take positive action toward adherence. ${ }^{33}$ In contrast, non-supportive social networks can alter health habits by introducing stress that compromises the attitudes and behaviours necessary for adherence. ${ }^{34}$

In literature, social support can be perceived differently based on the recipient's gender, racial or ethnic background, or cultural practices. ${ }^{14}$ Socially isolated ethnic

\begin{tabular}{|l|c|c|c|c|}
\hline Table 6. Risk of bias in randomized controlled studies \\
\hline Methodological quality criteria & 25 & 27 & 24 & 29 \\
\hline $\begin{array}{l}\text { Is randomization appropriately } \\
\text { performed? }\end{array}$ & Yes & Yes & Yes & Yes \\
$\begin{array}{l}\text { Are the groups comparable at } \\
\text { baseline? }\end{array}$ & No & Yes & Yes & Yes \\
\hline Are there complete outcome data? & Yes & Yes & Yes & Yes \\
\hline $\begin{array}{l}\text { Are outcome assessors blinded to } \\
\text { the intervention provided? }\end{array}$ & No & Yes & No & No \\
\hline $\begin{array}{l}\text { Did the participants adhere to the } \\
\text { assigned intervention? }\end{array}$ & Yes & Yes & Yes & Yes \\
\hline Total score; \% high quality & 80 & 100 & 90 & 90 \\
\hline
\end{tabular}

minority groups have been reported to be at increased risk of serious chronic illnesses and non-adherence behaviour to treatments. ${ }^{35}$ However, no attention has been paid in the included studies in this review to address issues in ethnic minority groups. This suggests the need for future interventional studies to target these populations to increase social support or strengthen family connectedness to improve medication adherence and overall health outcomes given the higher prevalence of hypertension and poorer health outcomes among some of these populations.

Although healthcare support is not as effective for patients as support obtained from their families and friends, healthcare providers should verify if patients are receiving the support they need and educate them about the importance of getting the adequate support to improve their overall health and treatment adherence. Healthcare providers may also direct patients without families or friends toward supportive resources and social workers.

This review suggests that healthcare providers need to assess the type and quality of patient's relationships in order to assist them receiving the most benefit from medical treatment. ${ }^{36}$ Recognizing the sources of social support which represent the key driver for changing patients' behaviour of taking medications would lead healthcare providers to align their health advice according to patients' needs and the support they have.

In addition, researchers need to be mindful to the impact of advances in technology such as mobile texting, tablet applications and online communities in diminishing social distancing between patients and their families or friends, and ultimately this may improve medication adherence in patients with hypertension. ${ }^{14}$

The limitations of this review are that there were only a small number of studies that met the inclusion criteria and data interpretation can include some bias. Nevertheless, the studies included reported consistent finding in terms of the beneficial role that social support from families, friends and professionals can have on patient medication adherence.

\section{CONCLUSIONS}

This review is the first to evaluate the impact of social support on medication adherence in hypertensive patients. Lack of social support has not been thoroughly addressed in the literature in terms of the significant role in may play in poor medication adherence. The findings of this review highlight the gap in the literature about social support and the importance of understanding the effect of this factor on 
medication adherence. In addition, addressing socia support in interventional studies are recommended. Healthcare providers need to understand the powerful effect social support from various sources can have on medication adherence when providing health advice to patients.

\section{CONFLICT OF INTEREST}

None.

\section{FUNDING}

None.

\section{AUTHOR ROLES (CRediT)}

Conceptualization : WS, GK, IS

Data curation: WS, GK, IS.

Formal analysis: WS, GK, IS.

Investigation: WS, IS.

Methodology: WS, GK.

Project administration: WS, GK, IS.

Supervision: GK, IS.

Visualization: WS, GK, IS.

Writing - original draft: WS, GK, IS.

Writing - review \& editing: WS, GK, IS.

\section{References}

1. Gallant MP. The influence of social support on chronic illness self-management: a review and directions for research. Health Educ Behav. 2003;30(2):170-195. https://doi.org/10.1177/1090198102251030

2. Abebe SM, Berhane Y, Worku A, Getachew A. Prevalence and associated factors of hypertension: a crossectional community based study in northwest ethiopia. PLoS One. 2015;10(4):e0125210. https://doi.org/10.1371/journal.pone.0125210

3. Ashoorkhani M, Majdzadeh R, Gholami J, Eftekhar H, Bozorgi A. Understanding Non-Adherence to Treatment in Hypertension: A Qualitative Study. Int J Community Based Nurs Midwifery. 2018;6(4):314-323.

4. Gwadry-Sridhar FH, Manias E, Lal L, et al. Impact of interventions on medication adherence and blood pressure control in patients with essential hypertension: a systematic review by the ISPOR medication adherence and persistence special interest group. Value Health. 2013;16(5):863-871. https://doi.org/10.1016/j.jval.2013.03.1631

5. Gast A, Mathes T. Medication adherence influencing factors-an (updated) overview of systematic reviews. Syst Rev. 2019;8(1):112. https://doi.org/10.1186/s13643-019-1014-8

6. McQuaid EL, Landier W. Cultural Issues in Medication Adherence: Disparities and Directions. J Gen Intern Med. 2018;33(2):200-206. https://doi.org/10.1007/s11606-017-4199-3

7. Cooper LA, Roter DL, Johnson RL, Ford DE, Steinwachs DM, Powe NR. Patient-centered communication, ratings of care, and concordance of patient and physician race. Ann Intern Med. 2003;139(11):907-915. https://doi.org/10.7326/00034819-139-11-200312020-00009

8. Turan GB, Aksoy M, Ciftcii B. Effect of social support on the treatment adherence of hypertension patients. J Vasc Nurs. 2019;37(1):46-51. https://doi.org/10.1016/i.jvn.2018.10.005

9. Ford ME, Tilley BC, McDonald PE. Social support among African-American adults with diabetes. Part 1: Theoretical framework. J Natl Med Assoc. 1998;90(6):361-365.

10. Adisa R, Olajide OO, Fakeye TO. Social Support, Treatment Adherence and Outcome among Hypertensive and Type 2 Diabetes Patients in Ambulatory Care Settings in southwestern Nigeria. Ghana Med J. 2017;51(2):64-77.

11. Costa Rdos S, Nogueira LT. Family support in the control of hypertension. Rev Lat Am Enfermagem. 2008;16(5):871-876. https://doi.org/10.1590/s0104-11692008000500012

12. Thomas P, Liu H, Umberson D. Family Relationships and Well-Being. Innovation in Aging. 2017;1(3):1-11. https://doi.org/10.1093/geroni/igx025

13. Cohen S. Social relationships and health. Am Psychol. 2004;59(8):676-684. https://doi.org/10.1037/0003-066x.59.8.676

14. Strom JL, Egede LE. The impact of social support on outcomes in adult patients with type 2 diabetes: a systematic review. Curr Diab Rep. 2012;12(6):769-781. https://doi.org/10.1007/s11892-012-0317-0

15. Stopford R, Winkley K, Ismail K. Social support and glycemic control in type 2 diabetes: a systematic review of observational studies. Patient Educ Couns. 2013;93(3):549-558. https://doi.org/10.1016/i.pec.2013.08.016

16. Bosworth HB, Olsen MK, Neary A, et al. Take Control of Your Blood Pressure (TCYB) study: a multifactorial tailored behavioral and educational intervention for achieving blood pressure control. Patient Educ Couns. 2008;70(3):338-347. https://doi.org/10.1016/i.pec.2007.11.014

17. Scheurer D, Choudhry N, Swanton KA, Matlin O, Shrank W. Association between different types of social support and medication adherence. Am J Manag Care. 2012;18(12):e461-e467.

18. Magrin ME, D'Addario M, Greco A, et al. Social support and adherence to treatment in hypertensive patients: a metaanalysis. Ann Behav Med. 2015;49(3):307-318. https://doi.org/10.1007/s12160-014-9663-2

19. Moher D, Liberati A, Tetzlaff J, Altman DG; PRISMA Group. Preferred reporting items for systematic reviews and metaanalyses: the PRISMA statement. BMJ. 2009;339:b2535. https://doi.org/10.1136/bmj.b2535

20. Hong QN, Fàbregues S, Bartlett G, et al. The Mixed Methods Appraisal Tool (MMAT) version 2018 for information professionals and researchers. Education for Information. 2018;34(4):1-7. https://doi.org/10.3233/EFI-180221

21. Olowookere AJ, Olowookere SA, Talabi AO, et al. Perceived family support and factors influencing medication adherence among hypertensive patients attending a Nigerian tertiary hospital. Ann Trop Med Public Health. 2015;8(6):241-245.

22. Khadoura K, Shakibazadeh E, Mansournia MA, Aljeesh Y, Fotouhi A. Determining the Prevalence of and the Factors Associated with Antihypertensive Medication Non-Adherence in the Gaza Strip. Korean J Fam Med. 2021;42(2):150-158. https://doi.org/10.4082/kifm.19.0081 
23. Haidari A, Moeini M, Khosravi A. The Impact of Peer Support Program on Adherence to the Treatment Regimen in Patients with Hypertension: A Randomized Clinical Trial Study. Iran J Nurs Midwifery Res. 2017;22(6):427-430. https://doi.org/10.4103/ijnmr.ijnmr $16 \quad 16$

24. Shen $Y$, Peng $X$, Wang $M$, et al. Family member-based supervision of patients with hypertension: a cluster randomized trial in rural China. J Hum Hypertens. 2017;31(1):29-36. https://doi.org/10.1038/jhh.2016.8

25. Hacihasanoglu Asilar R, Yildirim A, Saglam R, Demirturk Selcuk E, Erduran Y, Sarihan O. The effect of loneliness and perceived social support on medication adherence self-efficacy in hypertensive patients: An example of Turkey. J Vasc Nurs. 2020;38(4):183-190. https://doi.org/10.1016/j.jvn.2020.07.003

26. Pladevall M, Brotons $C$, Gabriel R, et al. Multicenter cluster-randomized trial of a multifactorial intervention to improve antihypertensive medication adherence and blood pressure control among patients at high cardiovascular risk (the COM99 study). Circulation. 2010;122(12):1183-1191. https://doi.org/10.1161/circulationaha.109.892778

27. Uchmanowicz B, Chudiak A, Uchmanowicz I, Rosińczuk J, Froelicher ES. Factors influencing adherence to treatment in older adults with hypertension. Clin Interv Aging. 2018;13:2425-2441. https://doi.org/10.2147/cia.s182881

28. Spikes T, Higgins M, Quyyumi A, Reilly C, Pemu P, Dunbar S. The Relationship Among Health Beliefs, Depressive Symptoms, Medication Adherence, and Social Support in African Americans With Hypertension. J Cardiovasc Nurs. 2019;34(1):44-51. https://doi.org/10.1097/jen.0000000000000519

29. Criswell TJ, Weber CA, Xu Y, Carter BL. Effect of self-efficacy and social support on adherence to antihypertensive drugs. Pharmacotherapy. 2010;30(5):432-441. https://doi.org/10.1592/phco.30.5.432

30. G/Tsadik D, Berhane Y, Worku A. Adherence to Antihypertensive Treatment and Associated Factors in Central Ethiopia. Int J Hypertens. 2020;2020:9540810. https://doi.org/10.1155/2020/9540810

31. Hatah E, Lim KP, Ali AM, Mohamed Shah N, Islahudin F. The influence of cultural and religious orientations on social support and its potential impact on medication adherence. Patient Prefer Adherence. 2015;9:589-596. https://doi.org/10.2147/ppa.s79477

32. Kurniawati ND, Wahyuni ED, Toulasik YA. Family support improves hypertensive patient drug compliance. Indian J Public Health Res Develop. 2019;10(8):2660-2665.

33. Wallston BS, Alagna SW, DeVellis BM, et al. Social support and physical health. Health Psychology. 1983;2(4):367-391. https://doi.org/10.1037/0278-6133.2.4.367

34. Kaplan RM, Hartwell SL. Differential effects of social support and social network on physiological and social outcomes in men and women with type II diabetes mellitus. Health Psychol. 1987;6(5):387-398. https://doi.org/10.1037//0278$\underline{6133.6 .5 .387}$

35. Smith EMJ. Ethnic Minorities: Life Stress, Social Support, and Mental Health Issues. The Counseling Psychologist. 1985;13(4):537-579. https://doi.org/10.1177\%2F0011000085134002

36. DiMatteo MR. Social support and patient adherence to medical treatment: a meta-analysis. Health Psychol. 2004;23(2):207-218. https://doi.org/10.1037/0278-6133.23.2.207 